\title{
O ensino de graduação em enfermagem durante a pandemia da COVID-19
}

\author{
Undergraduate nursing education during the COVID-19 pandemic \\ Educación de pregrado en enfermería durante la pandemia de \\ COVID-19
}

\begin{abstract}
Como citar este artigo: Araújo, Agostinho Antônio Cruz; Amaral, Jackeline Vieira; Araujo Filho, Augusto Cezar Antunes de; Nunes, Benevina Maria Vilar Teixeira. O ensino de graduação em enfermagem durante a pandemia da COVID-19. Revista Cuidarte. 2021;12(1):e1290. http://dx.doi.org/10.15649/cuidarte.1290
\end{abstract}

Revista Cuidarte doij http://dx.doi.org/10.15649/cuidarte.1290

E-ISSN: 2346-3414
(1) Agostinho Antônio Cruz Araújo'
Jackeline Vieira Amaral
(1) Augusto Cezar Antunes de Araujo
Filho ${ }^{3}$
Benevina Maria Vilar Teixeira
Nunes ${ }^{4}$
1 Universidade Federal do
Piauí. Teresina, Brasil. E-mail:
agostinhocruz@outlook.com.br
2 Universidade Federal do
Piauí. Teresina, Brasil. E-mail:
jackelinevamaral@gmail.com
3 Universidade Estadual do
Piauí. Floriano, Brasil. E-mail:
augustoantunes@frn.uespi.br
4 Universidade Federal do
Piauí. Teresina, Brasil. E-mail:
benevina@ufpi.edu.br ORCID:

Estimado Editor,

O betacoronavirus SARS-CoV-2 surgiu em dezembro de 2019, na cidade de Wuhan, China'. Diante da fácil transmissibilidade do vírus, assim como a inexistência de meios para imunização da população e tratamento efetivo justificam a adesão de medidas de isolamento social a fim de combater o contágio pelo vírus.

Atualmente, diante da pandemia pelo novo coronavírus, notou-se que as Instituições de Ensino Superior (IES) tiveram que se adaptar para dar continuidade em algumas de suas atividades acadêmicas.

Atualmente, diante da pandemia pelo novo coronavírus, notouse que as Instituições de Ensino Superior (IES) tiveram que se adaptar para dar continuidade em algumas de suas atividades acadêmicas Um exemplo disso foi o retorno parcial das aulas nos programas de mestrado e doutorado, assim como a realização de cursos de capacitação e atualização e videoconferências.

A Educação à Distância (EaD) surge como possibilidade de educação para acadêmicos e profissionais por meio do compartilhamento de conhecimentos em qualquer lugar, sendo necessário apenas um meio para acesso².

A Portaria do Ministério da Educação n².117, de 6 de dezembro de 2019 regulamentou a carga horária para disciplinas oferecidas na modalidade EaD em cursos presenciais ofertados pelas IES pertencentes ao Sistema Federal de Ensino. Nesse documento tal proposta não pode ultrapassar $40 \%$ da carga horária total do

Recebido: junho 7 de 2020

Aceito: julho 10 de 2020

Publicado: novembro 13 de 2020

$\square *$ Correspondencia

Agostinho Antônio Cruz Araújo

E-mail:agostinhocruz@outlook.com.br 
curso. Ressalta-se que dentre a maioria dos cursos das áreas do conhecimento, o bacharelado em medicina é o único que não se enquadra nessa Portaria ${ }^{3}$.

No que diz respeito a enfermagem, atualmente, o uso de mídias sociais tem sido utilizado como forma de compartilhamento de diversas temáticas, ainda que contribua de forma positiva na atualização de determinados conhecimentos discussões, como também interação entre alunos de graduação, pós-graduação, professores e enfermeiros. Entretanto, nota-se que as particularidades na utilização dessas mídias devem ser consideradas, uma vez que o uso inadequado dessas se configuram como um fator que pode comprometer o processo de ensino-aprendizagem ${ }^{4}$.

Destarte, destaca-se a reflexão acerca do feedback dos alunos, uma vez que é uma forma de analisar a eficácia na utilização de tal ferramenta. Ademais, ressalta-se a importância na avaliação das limitações existentes no público-alvo das informações, visto que a desigualdade social é um desafio evidente no país. Com isso, o feedback pode ser considerado uma ferramenta relevante nessa modalidade de ensino, desde que as dificuldades de cada aluno sejam consideradas a ponto de proporcionar adaptações dos materiais fornecidos com o propósito de aprimorar tanto a qualidade como a acessibilidade às informações.

Em outra perspectiva, a Portaria do Ministério da Educação n 374, de 3 de abril de 2020 regulamentou sobre a antecipação na colação de grau de acadêmicos da área de saúde para atuação no combate a pandemia do novo coronavírus. Sobretudo para a enfermagem, tornase fundamental o cumprimento de $75 \%$ da carga horária. Assim, as atividades realizadas no combate a COVID-19 seriam atribuídas como complementação das horas do estágio obrigatório, a fim de gerar o diploma ${ }^{5}$.

Entretanto, este documento foi revogado pela Portaria n 383, de 9 de abril de 2020 que retirou o incentivo no acréscimo de $10 \%$ em provas programas de residência, além de retirar a obrigatoriedade dos formandos de atuarem diretamente em combate a pandemia. Todavia manteve-se a obrigatoriedade do cumprimento de $75 \%$ da carga horária do estágio obrigatório para solicitar a antecipação da colação de grau. Ademais, nota-se que a proposta do Ministério da Educação possui vigência equivalente a duração da emergência de saúde pública decorrente desse vírus ${ }^{6}$.

O Estágio Curricular Supervisionado (ECS) foi instituído por meio da Resolução n 3/2001 das Diretrizes Curriculares Nacionais (DCN) para os Cursos de Graduação em Enfermagem (CGE). Deve estar nos últimos dois períodos do curso e sua carga horária mínima deve ser equivalente a $20 \%$ da carga horária total do curso 7 .

Estudos evidenciam que ECS instiga o estudante a desenvolver competências gerenciais, como liderança, gestão e gerenciamento de recursos e o desempenho das funções burocráticas; compreensão crítica e ética sobre a enfermagem, além da possibilidade de aliar a teoria à prática profissional ${ }^{8,9}$.

Com isso, o ECS incentiva o estudante de enfermagem a buscar autonomia na realização de suas atividades, além disso, o auxilia em adquirir uma visão sobre os sistemas de saúde para que, assim, torne-se um agente transfor-
O ECS incentiva o estudante de enfermagem a buscar autonomia na realização de suas atividades 
mador da realidade em que esteja inserido. Por isso, recomenda-se discussões constantes sobre as metodologias de ensino utilizadas, visto ser uma consolidação no uso da prática e teoria nos serviços de saúde ${ }^{10}$.

Nota-se que o ECS se configura como período essencial para o acadêmico de enfermagem, uma vez que este terá oportunidade de vivenciar e aplicar os conhecimentos adquiridos durante sua vida acadêmica. Além disso, o estágio serve como um período de reflexões acerca de si mesmo, visto que a partir da análise de sua própria postura, o estudante pode identificar fatores para se aprimorar e, assim, possa desenvolver uma assistência com qualidade.

Assim, a pandemia do novo coronavírus trouxe a necessidade de implementação de novos modelos educacionais acessíveis para os estudantes e docentes. Por meio disso, será possível utilizar o tempo de forma útil, e aprofundar-se em áreas de seu interesse. Além disso, o pedido de antecipação de colação de grau, à primeira vista, pode ser tentador, entretanto, pode se tornar um fator que irá desencadear incerteza e insegurança pelo acadêmico de enfermagem.

Conflito de interesses: Os autores declaram que não há conflito de interesses.

\section{Referências}

1. Hongzhou L, Charles WS, Yi-Wei T. Outbreak of Pneumonia of Unknown Etiology in Wuhan China: the Mystery and the Miracle. J. Med. Vir. 2020;92:401-402.

https://doi.org/10.1002/jmv.25678

2. Silva AN, Santos AMG, Cortez EA, Cordeiro BC. Limites e possibilidades do ensino à distância $(\mathrm{EaD})$ na educação permanente em saúde: revisão integrativa. Ciênc. Saúde Colet. 2020;20(4):1099-1107. https://doi.org/10.1590/1413-81232015204.17832013

3. BRASIL. Ministério da Educação. Portaria n².117, de 6 de dezembro de 2019. Diário Oficial da União, Brasília, DF, 11 dez, 2019. Disponível em: http://www.in.gov.br/en/web/dou/-/portaria-n-2.117-de-6-de-dezembro-de-2019-232670913

4. Kakushi LE, Évora YDM. Social networking in nursing education: integrative literature review. Rev. Latino-Am. Enfermagem. 2016;24:e2709.

https://doi.org/10.1590/1518-8345.1055.2709

5. BRASIL. Ministério da Educação. Portaria no 374, de 3 de abril de 2020. Diário Oficial da União, Brasília, DF, 06 abr, 2020a. Disponível em: http://www.in.gov.br/web/dou/-/portarian-374-de-3-de-abril-de-2020-251289249

6. BRASIL. Ministério da Educação. Portaria no 383, de 9 de abril de 2020. Diário Oficial da União, Brasília, DF, 13 abr, 2020b. Disponível em: https://abmes.org.br/arquivos/legislacoes/Portaria-mec-383-2020-04-09.pdf

7. BRASIL. Ministério da Educação. Resolução № 3, de 07 de novembro de 2001. Institui Diretrizes Curriculares Nacionais do Curso de Graduação em Enfermagem. Conselho Nacional de Educação, 2001. Disponível em: http://portal.mec.gov.br/cne/arquivos/pdf/CES03.pdf

8. Rigobello JL, Bernardes A, Moura AA. Estágio Curricular Supervisionado e o desenvolvimento das competências gerenciais: a visão de egressos, graduandos e docentes. Esc. Anna Nery. 2018;22(2):e20170298. https://doi.org/10.1590/2177-9465-ean-2017-0298

9. Silva GO, Souza PM, Batista AN, Barbosa CDM, Barreto IS, Ribeiro LCM. Estágio Curricular Supervisionado em autarquia profissional: contribuições para a formação em Enfermagem. Enferm. Foco. 2019;10(6):205-211. https://doi.org/10.21675/2357-707X.2019.v10.n6.2763

10.Garcia SD, Vannuchi MTO, Garanhani ML, Sordi MRL. Internado de enfermería: conquistas y desafíos en la formación del enfermero. Trabalho, Educ. Saúde. 2018;16(1):319-336. https://doi.org/10.1590/1981-7746-sol00105 